\title{
Clinical evaluation and management of calcific tendinopathy: an evidence-based review
}

https://doi.org/10.1515/jom-2021-0213

Received August 25, 2021; accepted November 29, 2021; published online February 4, 2022

\begin{abstract}
Calcific tendinopathy (CT) is an important musculoskeletal condition most commonly seen in the shoulder girdle, accounting for $10-42 \%$ of all shoulder pain. Despite the high prevalence within the shoulder region, CT has been demonstrated in many tendons throughout the axial and appendicular skeleton. Unlike degenerative tendinopathies, CT appears to be a selflimiting condition that affects otherwise-healthy tendon with deposition of calcium hydroxyapatite crystals between healthy tenocytes. In patients with functionally limiting symptoms or pain, the clinical course may be accelerated through a multitude of treatments including physical therapy and pain management, extracorporeal shock wave therapy, ultrasound-guided percutaneous lavage (UGPL), and operative debridement. Currently, the most efficacious and frequently utilized treatment for shoulder CT is UGPL due to its ability to effectively reduce calcium burden and pain while limiting soft-tissue damage. However, more evidence regarding the treatment and course of CT is needed before determining the most appropriate treatment at all potential sites of CT.
\end{abstract}

Keywords: calcific tendinopathy; calcific tendonitis; evaluation; treatment; ultrasound.

*Corresponding author: Kelly C. McInnis, DO, Department of Physical Medicine and Rehabilitation and Division of Sports Medicine, Massachusetts General Hospital and Spaulding Rehabilitation Hospital/Harvard Medical School, Boston, MA, USA,

E-mail:kcmcinnis@partners.org

Michael Catapano, MD and Sean Schowalter, MD, Department of Physical Medicine and Rehabilitation, Spaulding Rehabilitation Hospital/Harvard Medical School, Boston, MA, USA.

https://orcid.org/0000-0003-3051-227X (M. Catapano)

David M. Robinson, MD, Department of Physical Medicine and Rehabilitation, Mayo Clinic, Rochester, MN, USA. https://orcid.org/ 0000-0003-4481-1246
Calcific tendinopathy (CT) is characterized by the deposition of calcium hydroxyapatite crystals within a pathologically healthy tendon [1]. This calcification differs from the calcification seen in degenerative tendinopathy, which is composed of a heterogenous mixture of calcium salts diffusely scattered throughout the tendon in areas of collagen degeneration or tear [1]. In contrast, CT calcification presents as a focal collation of calcium hydroxyapatite crystals in the 'critical zone', which is $1-2 \mathrm{~cm}$ from the insertion of a tendon [2], where there is thought to be high shear and stress forces that initiate the development of a focal calcific deposit between healthy collagen fibers [1].

CT has been described in innumerable tendons throughout the appendicular and axial skeleton [3]. However, CT has received renewed attention due to the high prevalence in the shoulder girdle, affecting $10-42 \%$ of the population [4-6], representing at least 33 million people in the United States alone [4-6]. Of the shoulder tendons, the supraspinatus tendon of the rotator cuff is most frequently affected, representing $80 \%$ of shoulder CT [7]. CT of the infraspinatus and subscapularis are seen less frequently, in 15 and 5\%, respectively [7]. Hip girdle tendons, including the reflected head of the rectus femoris and gluteus medius, are the second most commonly affected region, with a reported prevalence of 5.4\% [8]. Case studies have described CT in the proximal hamstring and biceps brachii as well as occasional descriptions in the longus colli, Achilles, and innumerable others [3, 9-12]. The high prevalence of shoulder CT has facilitated an improved understanding of the pathogenesis as well as the best practice approach to evaluation and evidence-driven treatment, which can be extrapolated to less frequently affected tendons [13].

Due to its presentation in otherwise-healthy tendons, CT is typically seen in younger patients, with most presenting in their 30 s to 50s. Women are more commonly affected with CT than men, and associated conditions include diabetes, hypothyroidism, and hyperlipidemia. This is in comparison to degenerative tendinopathy, whereby patients are typically in their late 50 s to 60 s, with $65 \%$ of patients reported to 
have imaging evidence of rotator cuff tendon degeneration at age 65 [14-17].

Patients with CT present in one of four pathological stages (formative, resting, resorptive, or reparative) of disease that tend to loosely correlate with clinical presentation. As patients progress through the pathological morphologies, symptoms progress from diffuse pain to focal impingement, and finally, severe localized pain prior to resolution. The introduction of point-of-care ultrasound (POCUS) has allowed for the individual tailoring of interventions to the pathological state, such as oral medical treatments, corticosteroid injection, ultrasound-guided percutaneous lavage (UGPL), extracorporeal shockwave therapy (ESWT), and surgical debridement and decompression. However, with ongoing technological and biomedical enhancements, the treatment of CT continues to evolve and presents an opportunity for ongoing improvements in diagnosis and treatment.

This paper aims to focus on the clinical evaluation of CT by reviewing the anatomy, pathophysiology, clinical presentation, examination, and approach to imaging as well as by providing an overview of evidence-based treatment options.

\section{Clinical summary}

\section{Anatomy and pathophysiology}

The composition of tendon architecture has been well described through animal models, surgical specimens, and cadaveric studies. Tendons are comprised of three basic building blocks: tenocytes, extracellular matrix, and collagen (primarily Type 1). Collagen is arranged in a hierarchy of tightly packed linear fibers surrounded by connective tissue sheaths of both the endotendon and epitendon $[18,19]$. Although tendons are primarily avascular with most of their nourishment coming extrinsically through diffusion from the surrounding connective tissues, tenocytes aid in tendon health by surveying for injury and secreting extracellular matrix when stimulated. Unlike degenerative tendinopathy, which results in the breakdown of type I collagen and subsequent diffuse intratendonous calcification [20], CT typically involves the formation of a single foci of calcium hydroxyapatite crystals embedded between grossly healthy fibrils of collagen [2]. The prevalent theory for the development of CT is a 'failed cell-mediated healing theory' [2, 21], whereby excessive loading conditions and repetitive microtrauma results in an aberrant healing response and focal calcification formation. As such, commonly loaded or injured tendons, including the supraspinatus, are more vulnerable. However, due to commonalities in structure and pathogenesis, any tendon throughout the body can be affected with CT.

The development of CT has been described by Uhthoff and Loerr [2] and Gosens et al. [22] to follow distinct stages of progression. First, the precalcific stage is characterized by the fibrocartilaginous metaplasia of tenocytes into chondrocytes, creating an environment in which calcifications can develop. The second, calcific stage, is subdivided into formative, resting, and resorptive phases. In the formative phase, calcium crystals are formed and coalesce into large foci of calcification, typically with a chalk-like appearance [2, 22]. The resting phase is characterized by a stable presence of mature calcifications surrounded by a fibrocartilaginous tissue border or 'cap'. Finally, in the resorptive phase, an inflammatory reaction to the calcific deposits occurs and vascularized tissue develops at the calcification periphery or cap [2, 22]. Resorption is mediated through macrophages and multinuclear giant cells, which infiltrate and phagocytose the calcific deposits. The calcification at this phase resembles toothpaste consistency and can leak into nearby bursae, bone, or muscle, causing severe pain [2, 22]. The last stage is the postcalcific/reparative phase, in which fibroblasts remodel the space previously occupied by calcium with Type III collagen. The Type III collagen is then replaced by Type I collagen, ultimately resulting in complete healing of the affected tendon and the restoration of tendon architecture [18].

\section{Clinical presentation and examination}

The clinical presentation and examination of CT is highly variable and depends on both the stage of the disease as well as the anatomic location [23]. Due to the higher prevalence of shoulder and hip CT, the stage-to-clinical correlations are based on these locations but can be extrapolated to any anatomic location in the body where CT develops [23].

As demonstrated on numerous imaging studies [24], a large percentage of patients with $\mathrm{CT}$ are asymptomatic, with little to no positive examination findings throughout the entire course of disease. Although the true prevalence of asymptomatic CT is unknown, asymptomatic shoulder CT has been proposed to affect $35-50 \%$ of the population [24]. As such, symptomology may vary significantly from patients who are completely asymptomatic to those presenting with acute, debilitating pain. In addition, patients 
may present at any stage of disease without symptoms of previous or subsequent stages. For example, one may present with acute-onset severe pain in the resorptive phase, with no prior symptoms in the formative phase. As always, clinical correlation with imaging findings is critical to ensure an accurate diagnosis.

Patients who present in the formative stage, in which calcium hydroxyapatite crystals form, typically describe a poorly localizable, subacute, low-grade pain that may be more pronounced or noticeable at night or with increased pressure in the area $[2,25]$. Physical examination in this phase may demonstrate vague pain that is provoked by shoulder movements, without localizable or specific findings $[2,25]$. Notably, for unknown reasons, a small subset of patients $(\sim 10 \%)$ may remain in a chronic formative phase with symptoms persisting for months to years unless treated $[15,23]$. However, most patients progress into the resting stage after 3-6 months. As stabilization of CT develops into a single calcific mass, symptoms become more mechanical secondary to the size of the lesion and the limited elasticity of the tendon. Patients presenting in the resting phase may complain of clicking, snapping, or catching sensations with joint motion and may have impingement and localizable pain with either stretch or recruitment of the affected tendon (Table 1) [26, 27]. As an example, those with supraspinatus CT may present with signs of rotator cuff impingement demonstrated by pain with abduction or with over-head activities in which the supraspinatus tendon, and the associated large calcific mass, become caught between the acromion and humeral head.

Classically, in shoulder and hip CT, patients present in the resorptive stage, the most painful stage of CT, and may present acutely, without symptoms at previous stages $[27,28]$. In the resorptive stage, due to inflammation with associated increased vascular flow and extrusion of calcium into nearby structures, patients tend to have localized swelling, erythema, and pain, with limited range of motion in their joints. The significant inflammatory reaction at this stage may mimic more aggressive osseous and articular conditions including septic arthritis [29,30]. During the transition from the resorptive to the reparative stage, patients will experience diminishing signs and symptoms until normal tendon structure and joint mechanics are restored.

\section{Diagnostic imaging}

\section{Plain radiographs}

Plain radiographs with standard joint-specific views can visualize $\mathrm{CT}$ in most cases, in addition to ruling out more ominous osseous abnormalities. Radiographic morphology can also be utilized in evaluating the stage of СT (Table 1 , Figure 1) [22, 28].

There are multiple radiographic classification systems for CT [31, 32]. The Gartner and Heyer classification system describes three unique deposit morphologies that correlate well with the histologic stage: (1) well circumscribed and dense (resting phase); (2) well circumscribed with an inhomogeneous structure or poorly circumscribed with a homogeneous structure (formative); and (3) poorly circumscribed and translucent (resorptive phase) [12, 27]. Plain radiographic findings may not correlate with the degree of symptoms or clinical improvement as similar initial symptoms and prognosis has been found regardless of location, size, and classification of calcifications on radiographs [33].

\section{Ultrasound}

Ultrasound is the other diagnostic imaging modality of choice for CT due to its superior ability to visualize CT at all stages and to guide therapeutic interventions [3, 34]. Sonographically, CT appears as a hyperechoic focus within the fibular pattern of healthy tendon, with posterior acoustic shadowing. Calcifications in CT can take on multiple forms that have been shown to correlate with pathological state. Hyperechoic arc-shaped deposits are characteristic of the resting phase and typically require more aggressive treatment such as UGPL or ESWT, owing to lower rates of spontaneous resolution. Non-arc shaped, fragmented, or nodular calcifications with increased color Doppler signal are indicative of the resorptive phase, in which spontaneous resolution is common and management with nonsteroidal anti-inflammatories (NSAIDs) and physical therapy is often successful. Ultrasonographic findings associated with symptomatic CT include fragmentation, power Doppler signal, and distention or extrusion of calcium into surrounding bursal structures $[35,36]$. However, similar to plain radiographs, although the appearance of calcifications on ultrasound may correlate with pathological stage and help guide treatment, findings may not correlate with the degree of symptoms [37]. In addition, although ultrasound is most commonly utilized for CT surrounding the shoulder and distal extremities due to the superficial locations [38], it may still be diagnostic for deeper structures, including those in the hip region or axial skeleton [38].

Newer scanning techinques, including compound scanning technology and elastography, hold promise for 
Table 1: Outline of expected physical examination findings, suggested radiographic views and CT mimics.

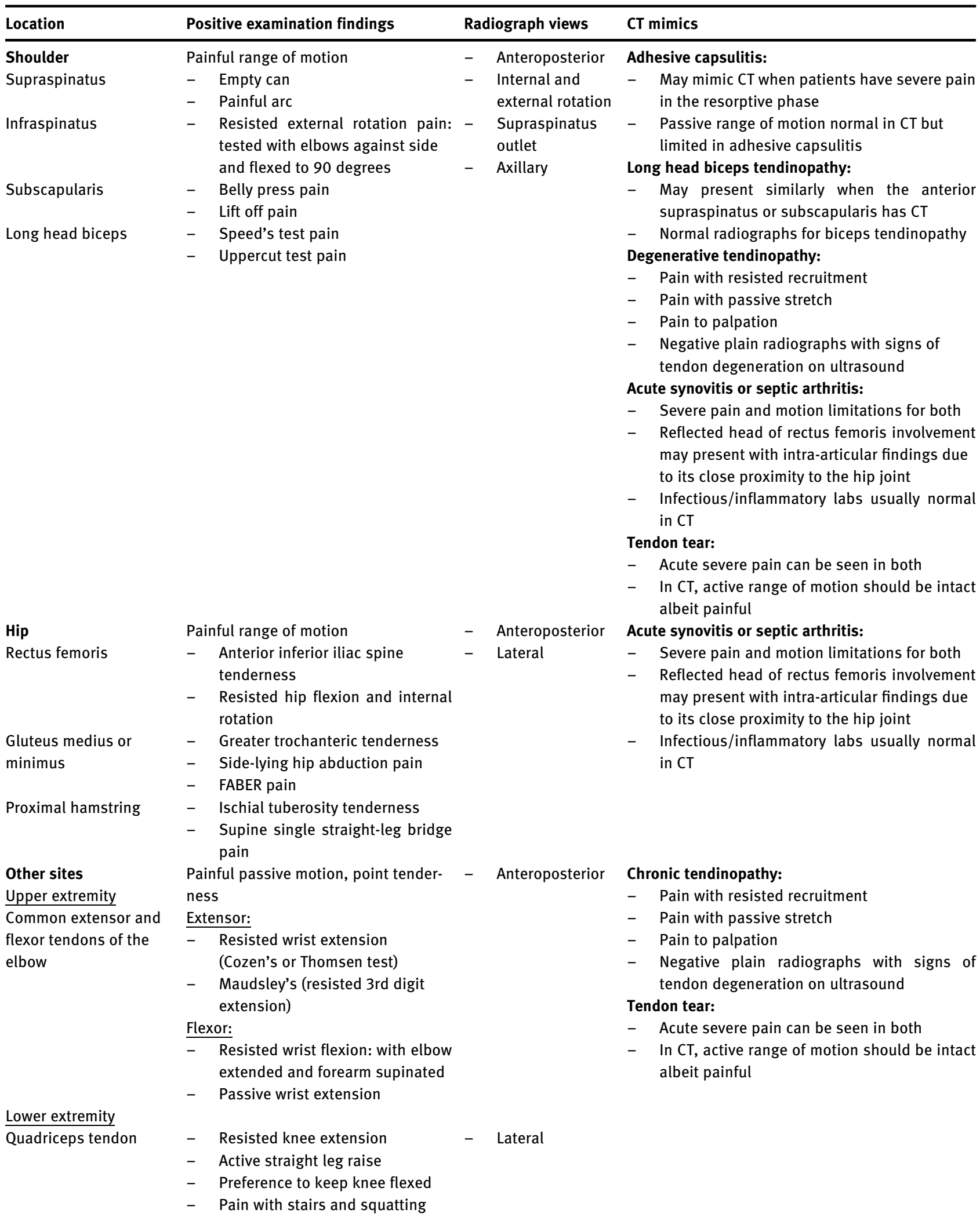


Table 1: (continued)

\begin{tabular}{llll}
\hline Location & Positive examination findings & Radiograph views & CT mimics \\
\hline Patellar tendon & - Resisted knee extension & - Lateral \\
Achilles tendon & - & Pain with squatting and jumping & \\
& - & Calf raises & \\
& - & Pain with running and possibly & \\
& walking & \\
\hline
\end{tabular}

$\mathrm{CT}$, calcific tendinopathy.

evaluation of CT but need more investigation before routine use $[35,36]$.

\section{Magnetic resonance imaging or arthrography (MRI/MRA)}

Unlike the superiority of MRI/MRA for the diagnosis of many musculoskeletal conditions, CT is difficult to visualize with standard MRI/MRA due to the similar signal hypointensity of calcifications compared to normal tendon. This leads to false-negatives and missed deposits or false-positives of normal hypointense, healthy tendons [39, 40]. MRI is often utilized to rule out other local joint and soft tissue pathology that may cause similar symptoms including tendon tears, osteoarthritis, and chondral or labral injury.

The advent of specialty sequences including susceptibility weighted imaging (SWI) has allowed for the improved diagnostic ability of MRI because calcifications appear hyperintense in contrast to the hypointensity of healthy tendon. Similar to ultrasound, calcifications are typically best seen in the coronal plane whereby the length of the tendon and the positioning of CT are best demonstrated. The use of SWI MRI is most commonly utilized for preoperative planning, whereby a diagnosis of CT has already been made and a precise three-dimensional (3D) localization of calcifications is needed for operative resection. Additionally, MRI has a high specificity for tendon and ligamentous tears as well as cartilaginous injuries that are important to identify and may be amenable to surgical repair or addressed intraoperatively.

\section{Treatment}

The treatment of CT follows a stepwise algorithm that begins with a nonoperative regimen of activity modification, anti-inflammatory medications, and physical therapy, and may progress to minimally invasive treatments including
UGPL and ESWT. For those with refractory symptoms, operative debridement and potential tendon repair are considered (Figure 2) [41]

\section{Nonoperative treatments}

Given the natural history of CT, whereby the natural course of disease concludes in complete resolution without residual tendon damage or degeneration, a trial of conservative therapy focused on symptomatic relief and functional improvement is utilized by most practitioners [42]. Although the following treatments are frequently utilized due to their low risk profile [43], there is little evidence regarding the individual efficacy or superiority of any particular treatment with regards to pain relief, improvements in function, or patient satisfaction.

Oral NSAIDs are commonly utilized due to their ability to provide relief through analgesia and reduction in inflammation [44]. Given no direct comparison studies, any NSAID and approved dosage can be considered, including topical NSAIDs, which have been demonstrated to result in lower systemic complications $[45,46]$. Duration of NSAID therapy should be limited, when possible, given the long-term gastrointestinal, renal, and cardiovascular side effects of chronic NSAID use [44]. Cimetidine is another oral medication that has been evaluated for CT and is theorized to alter parathyroid hormone activity and promote absorption of calcifications [47, 48] However, its use has only been reported in case series, and high-quality evidence for use in CT is currently lacking. Common side effects include headaches and drowsiness, as well as a rare risk of gynecomastia.

Despite the common use of physical therapy in CT, there has not been a specific exercise regimen that has been shown to be efficacious in CT. Only a handful of studies have investigated physical therapy in CT as a sole intervention [49-51]. However, due to the ubiquitous nature of shoulder pathologies, physical therapy has been utilized as a co-intervention or control group in the large majority of publications $[34,52,53]$. Described 

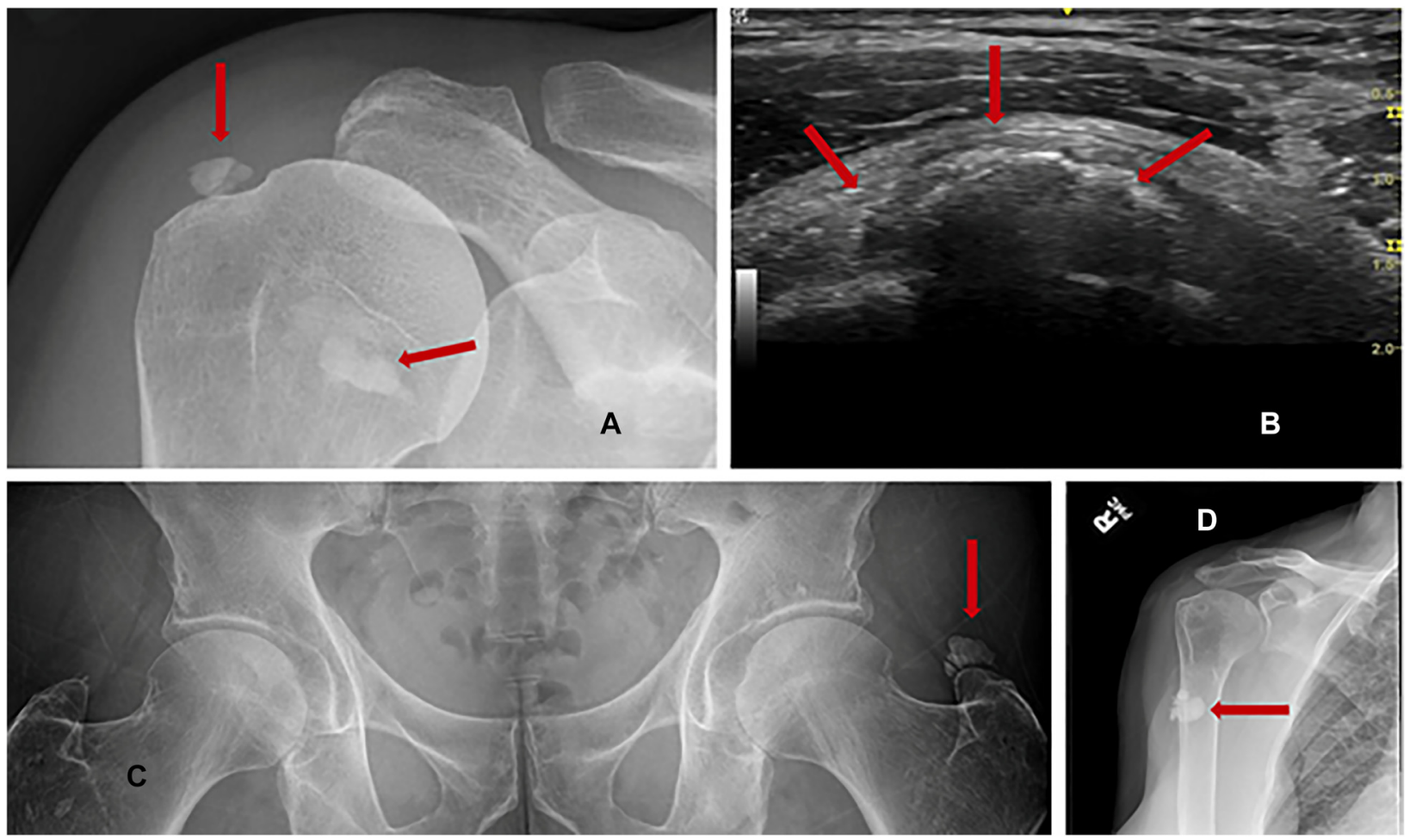

Figure 1: Plain radiograph and ultrasonograhic images of common calcific tendinopathy. (A) Plain anteroposterior (AP) radiograph of the shoulder demonstrating supraspinatus (superior arrow) and subscapularis (inferior arrow) CT seen as a radiopaque lesion near the greater tuberosity and lesser tuberosity, respectively. (B) Ultrasonographic image of supraspinatus CT demonstrating hyperechoic structure with posterior shadowing within the supraspinatus tendon. (C) Plain anteroposterior radiograph of the pelvis demonstrating gluteus medius $\mathrm{CT}$ seen as a radiopaque lesion near the greater trochanter. (D) Plain AP radiograph of the shoulder demonstrating biceps $\mathrm{CT}$ as a radiopaque lesion within the bicipital groove/anterior humerus. $\mathrm{CT}$, calcific tendinopathy.

techniques include a wide range of treatments consisting of range-of-motion exercises and aspects of periscapular and rotator cuff muscular strengthening [54-56]. The combination of these techniques is thought to preserve articular and tendon mobility while optimizing joint mechanics thereby decreasing dynamic tendon impingement. These techniques may be effectively extrapolated to any tendon affected by $\mathrm{CT}$, but there is currently not sufficient evidence to guide rehabilitation protocols.

Osteopathic manipulative therapy and/or friction massage can be recommended for appropriate patients with secondary somatic dysfunction, myofascial pain, and motion restriction with techniques that include counter-strain and muscle energy [57]. Although there is only preliminary evidence, the available literature has demonstrated a low potential for harm, with utilization in numerous studies for both controls and active groups [43, $57,58]$. In addition, several adjunctive modalities have been studied including therapeutic ultrasound, transcutaneous elective nerve stimulation (TENS), and acetic acid iontophoresis $[59,60]$. Although therapeutic ultrasound and TENS have demonstrated promise in providing pain relief, none of these modalities have definitively demonstrated improvements in pain, function, or time to condition resolution $[59,60]$. Overall, many noninvasive treatments have been evaluated for the treatment of CT, but there is limited evidence to recommend one specific treatment over another [61].

\section{Minimally invasive treatments}

Minimally invasive treatments or percutaneous techniques for the treatment of CT include isolated bursal or peritendinous injections, ESWT, and UGPL. For those in the resorptive phase, whereby there is already evidence of calcific resorption but there is continued limitation due to pain, additional pain relief can be achieved through an isolated bursal or peritendinous corticosteroid injection. Evidence for subacromial-subdeltoid corticosteroid injection (SAI) in a study of 21 patients with shoulder CT demonstrated $60 \%$ pain relief at 6 weeks and 3 months; however, there was a return to mean pain scores thereafter [37]. Notably, the ability of the tendon to regenerate 


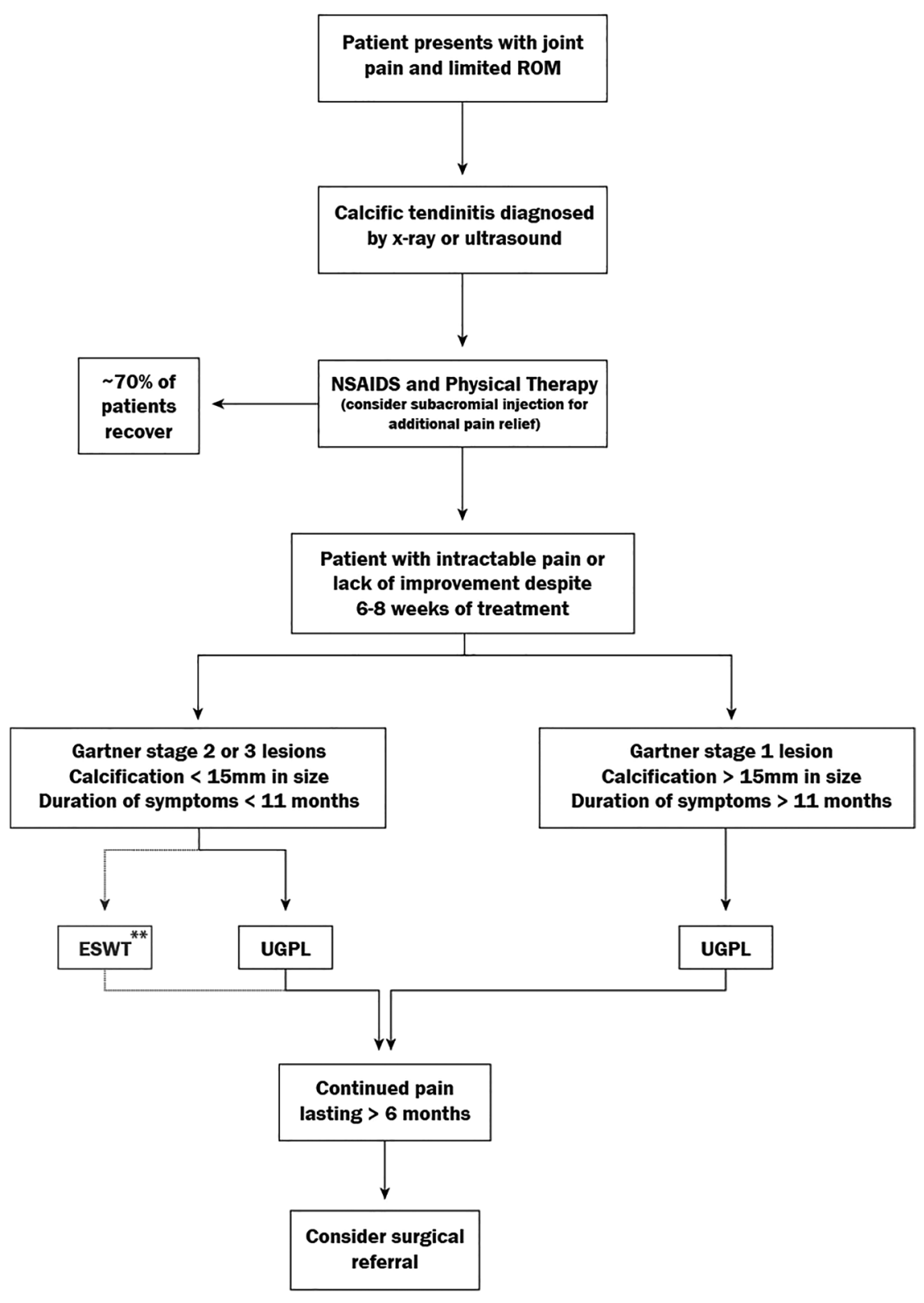

Figure 2: Treatment algorithm for those with calcific tendinopathy. UGPL is generally the preferred treatment over ESWT based on studies showing greater clinical benefit and greater reductions in the size of calcifications. Additionally, UGPL is typically covered by insurers in the United States, whereas ESWT is often an out-ofpocket expense. ESWT, extracorporeal shockwave therapy; NSAIDs, nonsteroidal anti-inflammatory drugs; UGPL, ultrasound-guided percutaneous lavage. or resorb calcific deposits is not hindered by the antiinflammatory or catabolic effects of the corticosteroid [37]. Therefore, the utilization of corticosteroid injections for pain relief in CT does not disrupt the natural disease course of tendon reconstitution.

Several individual studies as well as a network metaanalysis have demonstrated that ESWT, a technique in which sound waves are delivered to mechanically disrupt tissues, results in reduced pain and calcification size compared to nonoperative treatments including physiotherapy in those with shoulder CT [23, 49, 50, 62-64]. A few small studies have demonstrated that ESWT is most efficacious in those with smaller calcifications or at an earlier stage of disease. As such, it has been recommended that those with Gartner type I calcifications, calcification extent $>15 \mathrm{~mm}$, or duration of symptoms $>11$ months do not receive ESWT because these individuals do not reliably improve following therapy [65]. This may be due to the limitations of ESWT to disrupt or mobilize larger, more stabilized calcifications.

ESWT can be classified into "radial" (R-SWT) or "focused" (F-SWT), with differences in waveform characteristics and subsequent effect on the targeted tissue [52]. In addition, energy intensity levels during ESWT may be classified as low $\left(<0.08 \mathrm{~mJ} / \mathrm{mm}^{2}\right)$, medium $\left(0.08-0.28 \mathrm{~mJ} / \mathrm{mm}^{2}\right)$, or high $\left(>0.28 \mathrm{~mJ} / \mathrm{mm}^{2}\right)$ energy flux density [52]. Currently, there is more evidence needed to determine the most efficacious protocol of ESWT for CT. However, the authors 
suggest that based on the current literature, a high-energy protocol utilizing F-SWT, or a combination of F-SWT and R-SWT, may provide the most significant improvement in pain and calcification size $[52,62,66]$. In the United States, ESWT is typically an out-of-pocket expense, and this should be considered when assessing treatment options.

UGPL is perhaps the most studied and utilized treatment for painful cases of CT not responding to nonoperative treatments $[67,68]$. Prior meta-analyses have demonstrated that UGPL resulted in statistically and clinically significant improvement in both pain and radiographic resolution when compared to placebo, isolated corticosteroid injection, or ESWT in shoulder CT [53, 69]. Mean reductions in Visual Analogue Scale (VAS) of 3.14 (95\% CI 5.64-0.64) were seen, with an increase in resolution demonstrated with complete resorption of calcific deposits in $45 \%$ of patients at 6 weeks and $86 \%$ of patients at 12 months post-treatment [23, 53, 63].

Despite the significant improvement with UGPL $[67,68]$, protocols vary regarding the technique, lavage solution, and whether SAI is administered, with no definitive evidence regarding superiority of individual techniques. The two predominant UGPL procedural approaches are the singleneedle and double-needle techniques. The single-needle technique involves a single puncture of the calcification, at which point the syringe plunger is pulsated to inject saline into the deposit and allow backflow of calcium into the syringe when pressure is released. Syringes can be exchanged, and the technique is continued until the aspirated fluid is clear. Proponents of the single-needle technique contend that use of a single needle puts the patient at lower risk of infection, bleeding, and tendon trauma. The double-needle technique utilizes a second needle to aspirate the fluid introduced by the first needle. This creates a continuous influx and outflow of saline to remove calcium. Proposed benefits of the double-needle technique include greater fragmentation of the calcium deposition due to the introduction of two needles, and lower saline pressures within the calcifications (because saline is removed at the same rate it is injected). Theoretically, lesser intra-deposit pressures may reduce the risk of calcium spreading into the surrounding tendon and bursa, thereby decreasing the risk of postprocedural bursitis. One trial comparing these two techniques in 211 patients found no difference in the ease of calcium dissolution, calcification appearance, or clinical outcomes [70]. Although no statistically significant difference was found between these two techniques and postprocedural bursitis, there was a trend toward increased postprocedural bursitis in the one-needle technique group.

One large randomized trial demonstrated that warm saline $\left(42^{\circ} \mathrm{C}, 107.6^{\circ} \mathrm{F}\right)$ led to faster procedural times, easier calcium dissolution, and less subacromial bursitis compared to room-temperature saline in 462 patients [71]. However, a recent systematic review of 18 studies found that there continues to be limited evidence to definitively support the use of warmed lavage solution [72]. Sodium thiosulfate, a medication utilized in the treatment of calciphylaxis, did not provide benefit over normal saline [73]. In addition, although some providers often administer a corticosteroid injection after lavage, it has only been shown to be beneficial in those utilizing a single-needle technique [74, 75]. Although SAI is the most common type of bursal injection due to the predominance of shoulder CT, a bursal (trochanteric for gluteus medius) or peritendinous (common wrist extensors, proximal hamstring, etc.) injection may be performed. Corticosteroid injections are generally not administered around distal load-bearing tendons including the Achilles tendon.

Given the above evidence, the authors utilize and recommend a single-needle technique, UGPL, with a postprocedural bursal injection to reduce the risk of postprocedural bursitis. Utilizing this technique, study outcomes demonstrate complete resorption of calcific deposits in nearly half of patients by 6 weeks and the large majority by 1 year $[61,63,68]$.

\section{Operative treatments}

Operative intervention may be considered for patients who fail nonoperative management strategies and suffer from chronic pain lasting greater than 6 months. The goal of operative management is to debride and maximally remove calcifications while preserving tendon integrity. As such, local lavage after debridement is commonly performed in order to wash out any remaining calcium fragments within the joint space or local tissues and prevent secondary joint or tissue stiffness [76, 77]. However, patients should be counseled that improvements postsurgically may be slow because many studies report significant improvements in pain and function starting at 3-6 months postoperatively [76, 77].

Commonly, surgeons opt for arthroscopic approaches over open approaches to limit associated tissue damage; however, this is highly dependent upon anatomic location. Procedures for tendons located more superficially, including the Achilles tendon, have been described utilizing an open operative approach because there is easy tendon access with little intervening muscle or soft tissue [78]. Alternatively, deeper tendons, including the rectus femoris tendon, are often approached arthroscopically to limit local muscle trauma and ensure a shorter recovery 
time $[23,79]$. Regardless of the operative approach, the use of intraoperative ultrasound has gained popularity due to its ability to localize calcific deposits resulting in reductions in procedural time, number of portals, and length of operative field/incision [80].

\section{Conclusions}

CT is a common pathology characterized by the deposition of calcium hydroxyapatite crystals within a healthy tendon. Although CT is most frequently seen in tendons surrounding the shoulder, it can present in any tendon throughout the axial and appendicular skeleton. CT typically progresses through four stages consisting of the formative, resting, resorptive, and reparative stages. Patients most commonly present in the resorptive phase of the condition, whereby there is resorption of the calcium deposits resulting in significant inflammation associated with pain and limited function. Ultrasound and plain radiographs continue to be the gold standard for the diagnosis of CT and can be useful in guiding staged-treatment. Current nonoperative management strategies consist of oral NSAIDs and physical therapy for those that are in the reparative phase or not significantly functionally limited. Those with resistant disease may require SAI, UGPL, and ESWT. The best results have been demonstrated with UGPL. Operative debridement is reserved for those failing all previous treatments.

Research funding: None reported.

Author contributions: All authors provided substantial contributions to conception and design, acquisition of data, or analysis and interpretation of data; M.C., D.M.R., and S.S. drafted the article or revised it critically for important intellectual content; K.C.M. gave final approval of the version of the article to be published; and all authors agree to be accountable for all aspects of the work in ensuring that questions related to the accuracy or integrity of any part of the work are appropriately investigated and resolved.

Competing interests: None reported.

\section{References}

1. Riley GP, Harrall RL, Constant CR, Cawston TE, Hazleman BL. Prevalence and possible pathological significance of calcium phosphate salt accumulation in tendon matrix degeneration. Ann Rheum Dis 1996;55:109-15.

2. Uhthoff HK, Loehr JW. Calcific tendinopathy of the rotator cuff: pathogenesis, diagnosis, and management. J Am Acad Orthop Surg 1997;5:183-91.
3. Draghi F, Cocco G, Lomoro P, Bortolotto C, Schiavone C. Nonrotator cuff calcific tendinopathy: ultrasonographic diagnosis and treatment. J Ultrasound 2020;23:301-15.

4. Darrieutort-Laffite C, Blanchard F, Le Goff B. Calcific tendonitis of the rotator cuff: from formation to resorption. Jt Bone Spine 2018; 85:687-92.

5. Sansone V, Consonni O, Maiorano E, Meroni R, Goddi A. Calcific tendinopathy of the rotator cuff: the correlation between pain and imaging features in symptomatic and asymptomatic female shoulders. Skeletal Radiol 2016;45:49-55.

6. Reynolds A. Imaging the injured shoulder. Radiol Technol 2012; 83:261-88.

7. Uhthoff HK, Sarkar K. Calcifying tendinitis. Baillieres Clin Rheumatol 1989;3:567-81.

8. Park SM, Baek JH, Ko YB, Lee HJ, Park KJ, Ha YC. Management of acute calcific tendinitis around the hip joint. Am J Sports Med 2014;42:2659-65.

9. Pesquer L, Poussange N, Sonnery-Cottet B, Graveleau N, Meyer P, Dallaudiere B, et al. Imaging of rectus femoris proximal tendinopathies. Skeletal Radiol 2016;45:889-97.

10. Williams AA, Stang TS, Fritz J, Papp DF. Calcific tendinitis of the gluteus maximus in a golfer. Orthopedics 2016;39:e997-1000.

11. Doucet C, Gotra A, Reddy SMV, Boily M. Acute calcific tendinopathy of the popliteus tendon: a rare case diagnosed using a multimodality imaging approach and treated conservatively. Skeletal Radiol 2017;46:1003-6.

12. Albano D, Coppola A, Gitto S, Rapisarda S, Messina C, Sconfienza LM. Imaging of calcific tendinopathy around the shoulder: usual and unusual presentations and common pitfalls. Radiol Med 2021;126:608-19.

13. Lanza E, Banfi G, Serafini G, Lacelli F, Orlandi D, Bandirali M, et al. Ultrasound-guided percutaneous irrigation in rotator cuff calcific tendinopathy: what is the evidence? A systematic review with proposals for future reporting. Eur Radiol 2015;25:2176-83.

14. Mavrikakis ME, Drimis S, Kontoyannis DA, Rasidakis A, Moulopoulou ES, Kontoyannis S. Calcific shoulder periarthritis (tendinitis) in adult onset diabetes mellitus: a controlled study. Ann Rheum Dis 1989;48:211-4.

15. Harvie P, Pollard TCB, Carr AJ. Calcific tendinitis: natural history and association with endocrine disorders. J Shoulder Elbow Surg 2007;16:169-73.

16. Can B, Kara M, Kara Ö, Ülger Z, Frontera WR, Özçakar L. The value of musculoskeletal ultrasound in geriatric care and rehabilitation. Int J Rehabil Res 2017;40:285-96.

17. Lin TT-L, Lin CH, Chang CL, Chi CH, Chang ST, Sheu WHH. The effect of diabetes, hyperlipidemia, and statins on the development of rotator cuff disease. Am J Sports Med 2015;43:2126-32.

18. Thankam FG, Dilisio MF, Gross RM, Agrawal DK. Collagen I: a kingpin for rotator cuff tendon pathology. Am J Transl Res 2018; 10:3291-309.

19. Holmes DF, Lu Y, Starborg T, Kadler KE. Collagen fibril assembly and function. Curr Top Dev Biol 2018;130:107-42. Elsevier Inc.

20. Kim SJ, Song DH, Park JW, Park S, Kim SJ. Effect of bone marrow aspirate concentrate-platelet-rich plasma on tendon-derived stem cells and rotator cuff tendon tear. Cell Transplant 2017;26: 867-78.

21. Rui YF, Lui PPY, Chan LS, Chan KM, Fu SC, Li G. Does erroneous differentiation of tendon-derived stem cells contribute to the pathogenesis of calcifying tendinopathy? Chin Med J (Engl) 2011; 124:606-10. 
22. Gosens T, Hofstee DJ. Calcifying tendinitis of the shoulder: advances in imaging and management. Curr Rheumatol Rep 2009;11:129-34.

23. Louwerens JKG, Sierevelt IN, van Noort A, van den Bekerom MPJ. Evidence for minimally invasive therapies in the management of chronic calcific tendinopathy of the rotator cuff: a systematic review and meta-analysis. J Shoulder Elbow Surg 2014;23: 1240-9.

24. Porcellini G, Paladini P, Campi F, Paganelli M. Arthroscopic treatment of calcifying tendinitis of the shoulder: clinical and ultrasonographic follow-up findings at two to five years. J Shoulder Elbow Surg 2004;13:503-8.

25. Merolla G, Bhat MG, Paladini P, Porcellini G. Complications of calcific tendinitis of the shoulder: a concise review. J Orthop Traumatol 2015;16:175-83.

26. Kim M-S, Kim I-W, Lee S, Shin S-J. Diagnosis and treatment of calcific tendinitis of the shoulder. Clin Shoulder Elb 2020;23:210-6.

27. de Witte PB, van Adrichem RA, Selten JW, Nagels J, Reijnierse M, Nelissen RGHH. Radiological and clinical predictors of long-term outcome in rotator cuff calcific tendinitis. Eur Radiol 2016;26: 3401-11.

28. Siegal DS, Wu JS, Newman JS, del Cura JL, Hochman MG. Calcific tendinitis: a pictorial review. Can Assoc Radiol J 2009;60: 263-72.

29. Flemming DJ, Murphey MD, Shekitka KM, Temple HT, Jelinek JJ, Kransdorf MJ. Osseous involvement in calcific tendinitis: a retrospective review of 50 cases. Am J Roentgenol 2003;181: 965-72.

30. Porcellini G, Paladini P, Campi F, Pegreffi F. Osteolytic lesion of greater tuberosity in calcific tendinitis of the shoulder. J Shoulder Elbow Surg 2009;18:210-5.

31. Maier M, Schmidt-Ramsin J, Glaser C, Kunz A, Küchenhoff H, Tischer T. Intra- and interobserver reliability of classification scores in calcific tendinitis using plain radiographs and CT scans. Acta Orthop Belg 2008;74:590-5.

32. Gärtner J, Heyer A. [Calcific tendinitis of the shoulder]. Orthopade 1995;24:284-302.

33. Cho NS, Lee BG, Rhee YG. Radiologic course of the calcific deposits in calcific tendinitis of the shoulder: does the initial radiologic aspect affect the final results? J Shoulder Elbow Surg 2010;19:267-72.

34. Erickson JL, Jagim AR. Ultrasonic tenotomy and debridement for calcific tendinopathy of the shoulder: a pilot case series. J Prim Care Community Health 2020;11. https://doi.org/10.1177/ 2150132720964665.

35. Lin $\mathrm{CH}$, Chao HL, Chiou HJ. Calcified plaque resorptive status as determined by high-resolution ultrasound is predictive of successful conservative management of calcific tendinosis. Eur J Radiol 2012;81:1776-81.

36. Chiou HJ, Chou YH, Wu JJ, Huang TF, Ma HL, Hsu CC, et al. The role of high-resolution ultrasonography in management of calcific tendonitis of the rotator cuff. Ultrasound Med Biol 2001;27: 735-43.

37. Le Goff B, Berthelot JM, Guillot P, Glémarec J, Maugars Y. Assessment of calcific tendonitis of rotator cuff by ultrasonography: comparison between symptomatic and asymptomatic shoulders. Jt Bone Spine 2010;77:258-63.

38. Sconfienza LM, Albano D, Allen G, Bazzocchi A, Bignotti B, Chianca V, et al. Clinical indications for musculoskeletal ultrasound updated in 2017 by European Society of
Musculoskeletal Radiology (ESSR) consensus. Eur Radiol 2018; 28:5338-51.

39. Nörenberg D, Walter T, Ockert B, Knobloch G, Diederichs G, et al. Diagnosis of calcific tendonitis of the rotator cuff by using susceptibility-weighted MR imaging. Radiology 2016;278: 475-84.

40. Zubler C, Mengiardi B, Schmid MR, Hodler J, Jost B, Pfirrmann CWA, et al. MR arthrography in calcific tendinitis of the shoulder: diagnostic performance and pitfalls. Eur Radiol 2007;17: 1603-10.

41. Robinson D., Schwalter S, McInnis KC. Update on evaluation and management of calcific tendinopathy. Curr Phys Med Rehabil Rep 2021;9:57-69.

42. Ogon P, Suedkamp NP, Jaeger M, Izadpanah K, Koestler W, Maier $D$, et al. Prognostic factors in nonoperative therapy for chronic symptomatic calcific tendinitis of the shoulder. Arthritis Rheum 2009;60:2978-84.

43. Greis AC, Derrington SM, McAuliffe M. Evaluation and nonsurgical management of rotator cuff calcific tendinopathy. Orthop Clin North Am 2015;46:293-302.

44. Zheng X-Q, Li K, Wei YD, Tie HT, Yi XY, Huang W. Nonsteroidal anti-inflammatory drugs versus corticosteroid for treatment of shoulder pain: a systematic review and meta-analysis. Arch Phys Med Rehabil 2014;95:1824-31.

45. Scott A, Docking S, Vicenzino B, Alfredson H, Zwerver J, Lundgreen K, et al. Sports and exercise-related tendinopathies: a review of selected topical issues by participants of the second International Scientific Tendinopathy Symposium (ISTS) Vancouver 2012. Br J Sports Med 2013;47:536-44.

46. Devereaux M, Velanoski KQ, Pennings A, Elmaraghy A. Shortterm effectiveness of precut kinesiology tape versus an NSAID as adjuvant treatment to exercise for subacromial impingement: a randomized controlled trial. Clin J Sport Med 2016;26:24-32.

47. Kimura H, Iwamoto T, Oki S, Matsumura N, Nakamura M, Matsumoto M, et al. Chronic calcific periarthritis of the elbow treated by cimetidine administration: five cases. J Orthop Surg 2017;25. https://doi.org/10.1177/2309499017717193.

48. Yokoyama M, Aono H, Takeda A, Morita K. Cimetidine for chronic calcifying tendinitis of the shoulder. Reg Anesth Pain Med 2003; 28:248-52.

49. Carlisi E, Lisi C, Dall'angelo A, Monteleone S, Nola V, Tinelli C, et al. Focused extracorporeal shock wave therapy combined with supervised eccentric training for supraspinatus calcific tendinopathy. Eur J Phys Rehabil Med 2018;54:41-7.

50. Frizziero A, Vittadini F, Barazzuol M, Gasparre G, Finott P, Meneghini A, et al. Extracorporeal shockwaves therapy versus hyaluronic acid injection for the treatment of painful non-calcific rotator cuff tendinopathies: preliminary results. J Sports Med Phys Fitness 2017;57:1162-8.

51. Aytar A, Baltaci G, Uhl T, Tuzun H, Oztop P, Karatas M. The effects of scapular mobilization in patients with subacromial impingement syndrome: a randomized, double-blind, placebocontrolled clinical trial. J Sport Rehabil 2015;24:116-29.

52. Abo Al-Khair MA, El Khouly RM, Khodair SA, Al Sattar Elsergany MA, Hussein MI, Eldin Mowafy ME. Focused, radial and combined shock wave therapy in treatment of calcific shoulder tendinopathy. Phys Sportsmed 2021;49:480-7.

53. Arirachakaran A, Boonard M, Yamaphai S, Prommahachai A, Kesprayura S, Kongtharvonskul J. Extracorporeal shock wave 
therapy, ultrasound-guided percutaneous lavage, corticosteroid injection and combined treatment for the treatment of rotator cuff calcific tendinopathy: a network meta-analysis of RCTs. Eur J Orthop Surg Traumatol 2017;27:381-90.

54. Dilek B, Gulbahar S, Gundogdu M, Ergin B, Manisali M, Ozkan M, et al. Efficacy of proprioceptive exercises in patients with subacromial impingement syndrome. Am J Phys Med Rehabil 2016;95:169-82.

55. Abdulla SY, Southerst D, Côté P, Shearer HM, Sutton D, Randhawa K, et al. Is exercise effective for the management of subacromial impingement syndrome and other soft tissue injuries of the shoulder? A systematic review by the Ontario Protocol for Traffic Injury Management (OPTIMa) Collaboration. Man Ther 2015;20:646-56.

56. Littlewood C, Malliaras P, Mawson S, May S, Walters SJ. Selfmanaged loaded exercise versus usual physiotherapy treatment for rotator cuff tendinopathy: a pilot randomised controlled trial. Physiotherapy 2014;100:54-60.

57. Pfefer MT, Cooper SR, UhI NL. Chiropractic management of tendinopathy: a literature synthesis. J Manip Physiol Ther 2009; 32:41-52.

58. Tsertsvadze A, Clar C, Court R, Clarke A, Mistry H, Sutcliffe P. Costeffectiveness of manual therapy for the management of musculoskeletal conditions: a systematic review and narrative synthesis of evidence from randomized controlled trials. J Manip Physiol Ther 2014;37:343-62.

59. Leduc BE, Caya J, Tremblay S, Bureau NJ, Dumont M. Treatment of calcifying tendinitis of the shoulder by acetic acid iontophoresis: a double-blind randomized controlled trial. Arch Phys Med Rehabil 2003;84:1523-7.

60. Perron M, Malouin F. Acetic acid iontophoresis and ultrasound for the treatment of calcifying tendinitis of the shoulder: a randomized control trial. Arch Phys Med Rehabil 1997;78:379-84.

61. Wu Y-CC, Tsai W-CC, Tu Y-KK, Yu T-YY. Comparative effectiveness of nonoperative treatments for chronic calcific tendinitis of the shoulder: a systematic review and network meta-analysis of randomized controlled trials. Arch Phys Med Rehabil 2017;98: 1678-92. e6.

62. Farr S, Sevelda F, Mader P, Graf A, Petje G, Sabeti-Aschraf M, M. Extracorporeal shockwave therapy in calcifying tendinitis of the shoulder. Knee Surg Sports Traumatol Arthrosc 2011;19:2085-9.

63. Del Castillo-González F, Ramos-Alvarez JJ, Rodríguez-Fabián G, González-Pérez J, Jiménez-Herranz E, Varela E. Extracorporeal shockwaves versus ultrasound-guided percutaneous lavage for the treatment of rotator cuff calcific tendinopathy: a randomized controlled trial - PubMed. Eur J Phys Rehabil Med 2016;52:145-51.

64. Gazendam A, Ekhtiari S, Axelrod D, Gouveia K, Gyemi L, Ayeni O, et al. Comparative efficacy of nonoperative treatments for greater trochanteric pain syndrome: a systematic review and network meta-analysis of randomized controlled trials. Clin J Sport Med 2021. https://doi.org/10.1097/JSM.0000000000000924.

65. Chou WY, Wang CJ, Wu KT, Yang YJ, Ko JY, Siu KK. Prognostic factors for the outcome of extracorporeal shockwave therapy for calcific tendinitis of the shoulder. Bone Jt J 2017;99B:1643-50.

66. Ioppolo F, Tattoli M, Di Sante L, Attanasi C, Venditto T, Servidio M, et al. Extracorporeal shock-wave therapy for supraspinatus calcifying tendinitis: a randomized clinical trial comparing two different energy levels. Phys Ther 2012;92:1376-85.

67. de Witte PB, Selten JW, Navas A, Nagels J, Visser CPJ, Nelissen RGHH, et al. Calcific tendinitis of the rotator cuff: a randomized controlled trial of ultrasound-guided needling and lavage versus subacromial corticosteroids. Am J Sports Med 2013;41: 1665-73.

68. de Witte PB, Kolk A, Overes F, Nelissen RGHH, Reijnierse M. Rotator cuff calcific tendinitis: ultrasound-guided needling and lavage versus subacromial corticosteroids: five-year outcomes of a randomized controlled trial. Am J Sports Med 2017;45:3305-14.

69. Krasny C, Enenkel M, Aigner N, Wlk M, Landsiedl F. Ultrasoundguided needling combined with shock-wave therapy for the treatment of calcifying tendonitis of the shoulder. J Bone Jt Surg Ser B 2005;87:501-7.

70. Orlandi D, Mauri G, Lacelli F, Corazza A, Messina C, Silvestri E, et al. Rotator cuff calcific tendinopathy: randomized comparison of US-guided percutaneous treatments by using one or two needles. Radiology 2017;285:518-27.

71. Sconfienza LM, Bandirali M, Serafini G, Lacelli F, Aliprandi A, Di Leo $G$, et al. Rotator cuff calcific tendinitis: does warm saline solution improve the short-term outcome of double-needle USguided treatment? Radiology 2012;262:560-6.

72. Simpson M, Pizzari T, Cook T, Wildman S, Lewis J. Effectiveness of non-surgical interventions for rotator cuff calcific tendinopathy: a systematic review. J Rehabil Med 2020;52. https://doi.org/10. 2340/16501977-2725.

73. Darrieurtort-Laffite C, Bertrand-Vasseur A, Garraud T, Planche L, Le Goff B. Tolerance and effect of sodium thiosulfate in calcific tendinitis of the rotator cuff. Clin Rheumatol 2020;39: 561-9.

74. Darrieutort-Laffite C, Varin S, Coiffier G, Albert JD, Planche L, Maugars $\mathrm{Y}$, et al. Are corticosteroid injections needed after needling and lavage of calcific tendinitis? Randomised, doubleblind, non-inferiority trial. Ann Rheum Dis 2019;78:837-43.

75. Battaglia M, Guaraldi F, Gori D, Castiello E, Arvat E, Sudanese A. Efficacy of triamcinolone acetate and methylprednisolone acetonide for intrabursal injection after ultrasound-guided percutaneous treatment in painful shoulder calcific tendonitis: a randomized controlled trial. Acta Radiol 2017;58:964-70.

76. Cho CH, Bae KC, Kim BS, Kim HJ, Kim DH. Recovery pattern after arthroscopic treatment for calcific tendinitis of the shoulder. Rev Chir Orthop Traumatol 2020;106:395.

77. Lee TK, Shin SJ. Functional recovery of the shoulder after arthroscopic treatment for chronic calcific tendinitis. Clin Shoulder Elb 2018;21:75-81.

78. Shakked RJ, Raikin SM. Insertional tendinopathy of the Achilles: debridement, primary repair, and when to augment. Foot Ankle Clin 2017;22:761-80.

79. Comba F, Piuzzi NS, Zanotti G, Buttaro M, Piccaluga F. Endoscopic surgical removal of calcific tendinitis of the rectus femoris: surgical technique. Arthrosc Tech 2015;4:e365-9.

80. Sabeti M, Schmidt M, Ziai P, Graf A, Nemecek E, SchuellerWeidekamm C. The intraoperative use of ultrasound facilitates significantly the arthroscopic debridement of calcific rotator cuff tendinitis. Arch Orthop Trauma Surg 2014;134:651-6. 